\title{
Modul Antena dengan Susunan Uniform untuk Sistem Antena Radar Generasi Kedua
}

\author{
Antenna Module with Uniform Array \\ for $2^{\text {nd }}$ Generation Radar Antenna System
}

\author{
Folin Oktafiani , Yussi Perdana Saputera, Yudi Yuliyus Maulana, Yuyu Wahyu \\ Pusat Penelitian Elektronika dan Telekomunikasi, Lembaga Ilmu Pengetahuan Indonesia \\ Komplek LIPI Gd 20, Jl Sangkuriang 21/54D, Bandung 40135, Indonesia \\ Email:oktafiani@gmail.com
}

\begin{abstract}
The purpose of this research is to design an antenna module with uniform array for 2 nd generation radar antenna system. The designed antenna module comprises of four sub-modules, which are arranged vertically. Each antenna sub-module consists of eight rectangular patches that are arranged horizontally using coaxial feed as the feeding technique located at the center of the sub-module. Each antenna patch is given the same power so that the antenna is uniformly arranged. The antenna module is printed on a duroid material with the $\varepsilon_{r}$ value of 2.2 and a thickness of $1.57 \mathrm{~mm}$. The measurement result shows that antenna module can operate at a frequency of $9.4 \mathrm{GHz}$ with Voltage Standing Wave Ratio (VSWR) less than 1.5. An antenna gain of $20.08 d B i$ can be obtained with a horizontal beamwidth of $10^{\circ}$ degrees and a vertical beamwidth of $20^{\circ}$.
\end{abstract}

Keywords: antenna, module, patch, uniform array, radar

\begin{abstract}
Abstrak
Pada penelitian ini dilakukan perancangan dan fabrikasi modul antena dengan susunan uniform untuk sistem antena radar generasi kedua. Modul antena yang dirancang terdiri dari empat buah sub-modul yang disusun secara vertikal. Sub-modul terdiri dari susunan delapan patch berbentuk persegi yang diatur sejajar ke arah horizontal dengan metode pencatuan coaxial feed pada titik tengah sub-modul. Setiap patch antena diberi daya yang sama sehingga susunan berbentuk uniform (seragam). Antena dicetak pada bahan duroid dengan nilai $\varepsilon_{r}$ 2,2 dengan ketebalan 1,57 mm. Hasil pengukuran antena menunjukkan bahwa antena dapat bekerja pada frekuensi 9,4 Ghz dengan nilai VSWR (Voltage Standing Wave Ratio) $\leq 1,5$. Gain antena yang didesain sebesar $20.08 \mathrm{dBi}$ dengan beamwidth horizontal $10^{\circ}$ dan beamwidth vertikal $20^{\circ}$.
\end{abstract}

Kata kunci : antena, modul, patch, susunan uniform, radar

\section{Pendahuluan}

ISRA (Indonesia Sea Radar) merupakan alat utama sistem pertahanan yang berfungsi sebagai sensor atau alat deteksi khususnya daerah pantai. ISRA dapat digunakan pada kapal perang yang berfungsi sebagai Radar LPI (Low Probability Intercept), yaitu sebuah operasi militer secara senyap sehingga Radar LPI tidak terdeteksi oleh pihak lawan. Salah satu komponen krusial dalam sistem radar adalah sistem antena [1]-[5], jika dianalogikan pada tubuh manusia maka sistem antena sebagai mata yang sangat vital. Sehingga apabila sistem antena bermasalah maka sistem radar secara langsung akan bermasalah.

Received: 19 November 2015; Revised: 17 Juni 2016; Accepted: 31 Mei 2016; Published online: 21 Nov 2016 (C)2016 INKOM 2016/16-NO427

DOI: http://dx.doi.org/10.14203/j.inkom.427
Sistem antena generasi pertama ISRA yang telah dikembangkan ditunjukkan pada Gambar 1 dibawah ini.

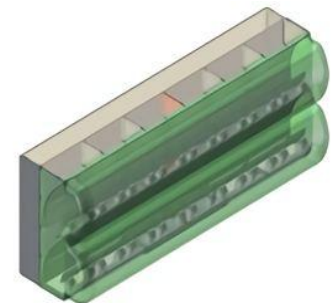

(a)

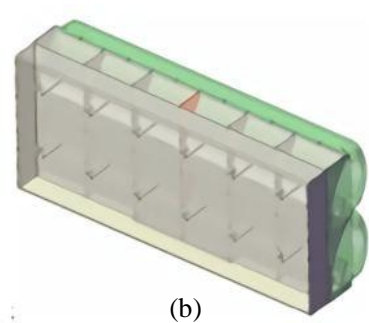

(b)
Gambar 1. Sistem antena radar generasi pertama

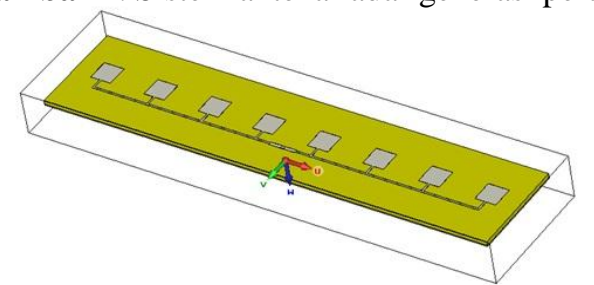

Gambar 2. Satu modul antena pada sistem antena radar generasi pertama 
Sistem antena radar generasi pertama mempunyai panjang $160 \mathrm{~cm}$ dan lebar $60 \mathrm{~cm}$. Sistem antena radar terdiri dari antena pemancar dan penerima yang bersifat identik.

Antena radar generasi pertama menggunakan antena mikrostrip. Antena mikrostrip merupakan salah satu jenis antena yang mempunyai kelebihan yaitu low profile, ringan, ukuran kecil, fabrikasi mudah dan murah, polarisasi linier maupun sirkuler, bentuknya yang compact sehingga cocok untuk komunikasi bergerak, dan dapat beroperasi pada single, dual maupun multiband [6]-[9].

Antena pemancar dan penerima generasi pertama terdiri dari susunan 8 buah modul antena yang disusun secara horizontal. Modul antena terdiri dari susunan 8 patch antena seperti terlihat pada gambar 2 .

Ukuran panjang dan lebar satu modul antena generasi pertama yaitu $57 \mathrm{~mm}$ x $190 \mathrm{~mm}$. Bentuk patch yang digunakan berbentuk persegi dengan ukuran $8,75 \mathrm{~mm} \times 8,75 \mathrm{~mm}$ yang bersesuaian dengan frekuensi 9,4 GHz. Penggunaan patch persegi dikarenakan polarisasi yang diinginkan dalam sistem antena adalah polarisasi linier.

Pencatuan dari modul antena generasi pertama menggunakan coaxial feed. Masing masing patch dihubungkan dengan saluran transmisi pada bagian bawah, kemudian ke delapan patch digabung dengan konfigurasi pencatuan di tengah atau dinamakan center feed [10].

Hasil pengukuran modul antena generasi pertama telah dipaparkan pada [11]. Nilai VSWR modul antena pada frekuensi $9.4181 \mathrm{GHz}$ diperoleh sebesar 1,0207. Hal ini sesuai spesifikasi awal dari antena dengan VSWR kurang dari 1,5. Hasil pengukuran koefisien refleksi pada frekuensi $9.4181 \mathrm{GHz}$ sebesar $-37,469 \mathrm{~dB}$. Gain modul antena generasi pertama dengan 8 buah patch sebesar 15,45 dB. Beamwidth horizontal dan vertikal modul antena generasi pertama yaitu $10^{\circ}$ dan $106.6^{\circ}$.

Untuk mempersempit beamwidth vertikal antena agar sesuai dengan spesifikasi yang diinginkan yaitu $20^{\circ}$ maka antena generasi pertama menggunakan reflektor dibagian belakang antena. Penambahan reflektor tersebut juga berpengaruh meningkatkan gain antena [12].

Salah satu permasalahan Radar ISRA generasi pertama adalah sistem antena yang terlalu lebar dan berat karena adanya reflektor berbahan plat aluminium dibagian belakang antena sehingga akan dibutuhkan motor dengan konsumsi daya yang lebih besar sehingga akan menambah biaya komponen.

Untuk mengatasi masalah tersebut maka pada makalah ini dipaparkan tentang desain suatu modul antena untuk sistem antena radar generasi kedua yang mempunyai performansi yang sama atau lebih baik dari sistem antena radar generasi pertama. Modul antena ini didesain untuk mempunyai nilai gain yang tinggi sehingga tidak memerlukan reflektor sebagai peningkat gain antena. Desain antena generasi kedua ini masih sama dengan generasi antena pertama yaitu tetap dengan menggunakan teknologi mikrostrip. Untuk meningkatkan gain dalam satu modul antena maka dilakukan penyusunan patch antena secara horizontal dan vertikal sehingga dengan banyaknya patch yang terdapat pada modul antena maka akan meningkatkan gain antena. Penyusunan patch secara horizontal dan vertikal juga dapat meningkatkan performansi beamwidth antena.

\section{Desain Antena}

Perancangan patch antena berbentuk persegi menggunakan persamaan di bawah ini untuk menentukan lebar patch $(W)$ optimum [13]:

$$
W=\frac{c}{2 f r} \sqrt{\frac{2}{\varepsilon_{r}+1}}
$$

$\varepsilon_{\mathrm{r}}$ merupakan konstanta dielektrik / relative permittivity dari substrat, c adalah kecepatan cahaya dalam ruang bebas sebesar $3.10^{8} \mathrm{~m} / \mathrm{s}$ dan $\mathrm{fr}$ adalah frekuensi kerja dari antena yang didesain. Dengan memperhitungkan pengaruh medan limpahan pada sisi yang meradiasi, panjang fisik $(L)$ antena dapat ditentukan dengan cara:

$$
L=\frac{c}{2 f r \sqrt{\varepsilon_{e f f}}}-2 \Delta L
$$

Dimana :

$\varepsilon_{\text {eff }}$ adalah konstanta dielektrik efektif, yakni:

$$
\varepsilon_{\text {eff }}=\frac{\varepsilon_{r}+1}{2}+\frac{\varepsilon_{r}-1}{2} \sqrt{\frac{1}{1+12 \frac{h}{W}}}
$$

$\Delta L$ adalah besarnya medan limpahan gelombang elektromagnet dari patch, yakni:

$$
\begin{gathered}
\frac{\Delta L}{h}=0.412 \frac{\left(\varepsilon_{\text {eff }}+0.3\right)\left(\frac{W}{h}+0.264\right)}{\left(\varepsilon_{\text {eff }}+0.258\right)\left(\frac{W}{h}+0.8\right)} \\
\Delta L=\left[0.412 \frac{\left(\varepsilon_{\text {eff }}+0.3\right)\left(\frac{W}{h}+0.264\right)}{\left(\varepsilon_{\text {eff }}+0.258\right)\left(\frac{W}{h}+0.8\right)}\right] h
\end{gathered}
$$

Dimana:

$$
\mathrm{h}=\text { tebal substrat }(\mathrm{mm}) \text {, }
$$$$
\mathrm{W}=\text { lebar patch }(\mathrm{mm}) \text {. }
$$ 


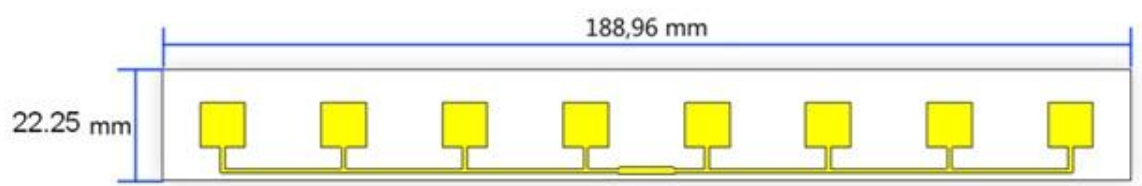

Gambar 3. Geometri sub-modul antena

Patch yang digunakan dalam modul antena berbentuk persegi dengan ukuran $8,75 \times 8,75 \mathrm{~mm}$ dengan jarak antar patch dalam satu sub-modul 1,475 mm dan jarak vertikal antar sub-modul 1,425 $\mathrm{mm}$. Geometri sub-modul antena ditunjukkan pada Gambar 3. Panjang dan lebar patch tersebut diperoleh dari hasil optimasi simulasi dengan ukuran awal berdasarkan perhitungan rumus tersebut diatas. Ukuran saluran transmisi yang menghubungkan antena patch satu dan lainnya dalam satu sub-modul yaitu panjang $3,4 \mathrm{~mm}$, sehingga menghasilkan fasa $80 \mathrm{rad}$, dan lebar 0.8 mm sehingga menghasilkan impedansi $70.71 \mathrm{ohm}$. Karakteristik pencatu yang digunakan mempunyai impedansi $50 \mathrm{ohm}$ sehingga ditambahkan penyesuai impedansi yang terletak di tengah submodul dengan ukuran panjang 3,4mm dan lebar
1,2 mm. Dengan ukuran tersebut akan menghasilkan impedansi $50 \mathrm{ohm}$ sehingga bersesuaian dengan karakteristik pencatu.

Satu modul terdapat empat baris sub-modul berupa susunan delapan patch secara horizontal, sehingga dalam satu modul terdapat 32 patch. Panjang satu modul antena adalah 188,96 mm dan lebar 22,25 mm. Gambar satu modul antena ditunjukkan pada Gambar 4. Dalam satu modul antena terdiri dari empat buah pencatu yang berfungsi sebagai sumber pencatu untuk tiap-tiap sub-modul. Teknik pencatuan dilakukan dengan metode coaxial feed dimana pencatuan dilakukan dari bagian groundplane antena yang kemudian menembus melalui substrat untuk terhubung dengan patch antena di bagian atas.

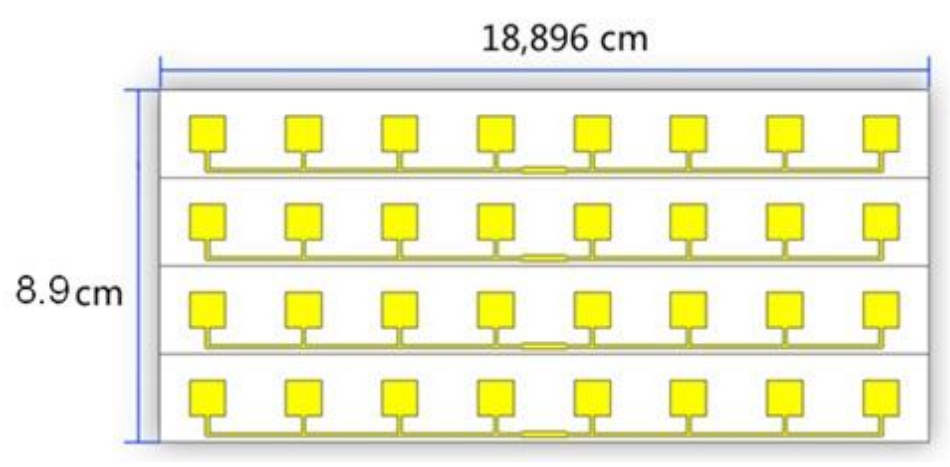

Gambar 4. Geometri modul antena

\section{Fabrikasi Antena}

Proses pencetakan antena dimulai dengan membuat film revro yang sesuai dengan desain antena yang telah kita buat, kemudian film tersebut disablon diatas substrat yang akan kita gunakan, langkah selanjutnya yaitu merendam substrat tersebut ke dalam larutan $\mathrm{FeCl}$ atau dikenal dengan istilah proses etching selama beberapa menit, hasil proses etching dibersihkan menggunakan air untuk menghilangkan sisa sisa larutan $\mathrm{FeCl}$ yang menempel pada substrat, sedangkan sisa sisa sablon yang menempel pada substrat dibersihkan dengan menggunakan larutan tertentu. Untuk mencegah kerusakan patch maka ditambahkan lapisan perak pada bagian patch dan groundplane. Modul antena yang telah difabrikasi dapat dilihat pada gambar 5 berikut ini

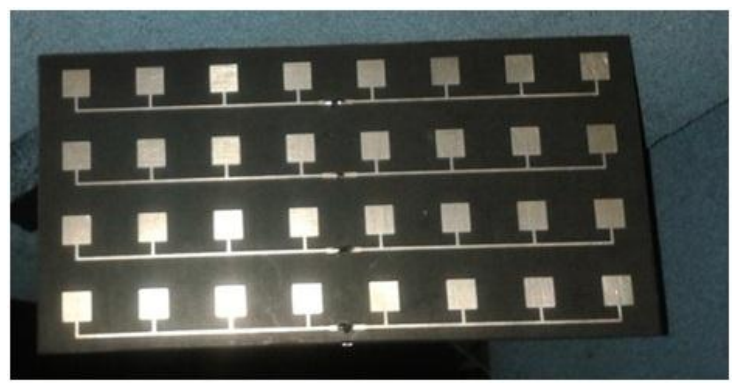

(a)

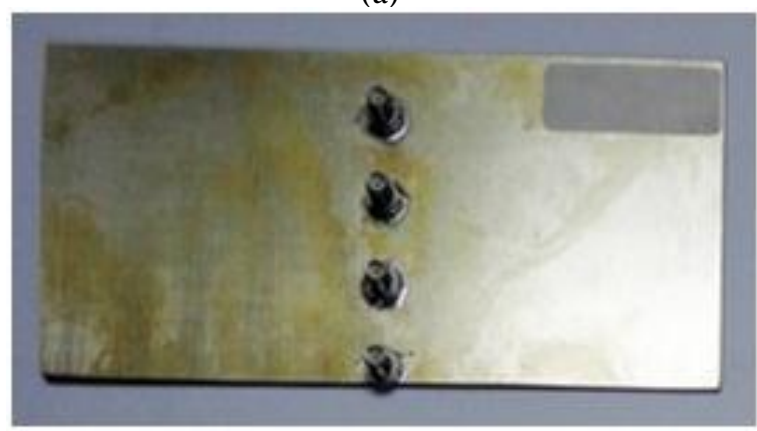

(b)

Gambar 5. Gambar fabrikasi modul antena (a). Tampak depan, (b). Tampak belakang 
Agar bekerja dengan maksimal maka modul modul yang sudah tersusun array tersebut harus terhubung menjadi satu untuk diberi umpan dengan sinyal masukan utama. Sebagai penghubung antar modul digunakan power divider/combiner 4:1. Power divider/combiner 4:1 terdiri dari empat input dan satu output pada sisi penerima dan satu input dan empat output pada sisi pengirim. Kabel semirigid digunakan sebagai penghubung antara pencatu dengan in/out combiner 4:1. Untuk menjaga agar jarak antar kabel semirigid tidak berubah digunakan penyangga seperti terlihat pada Gambar 6 .

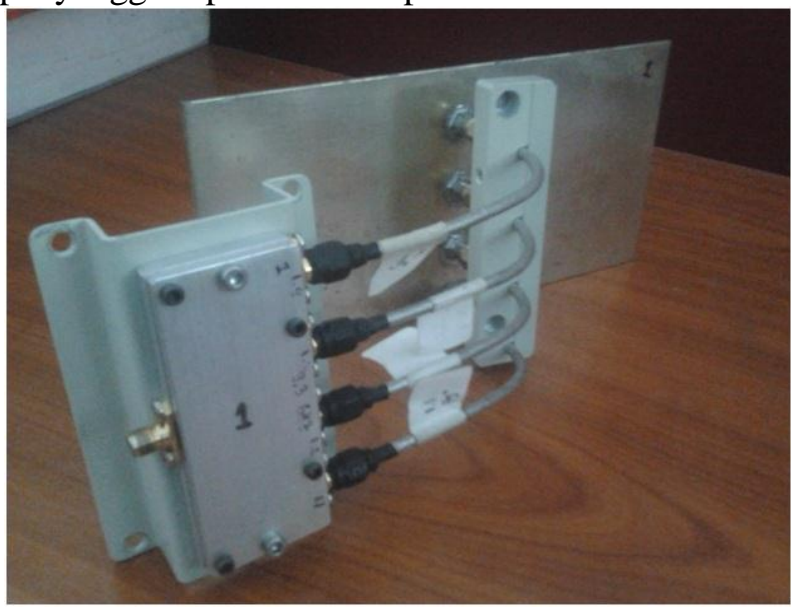

Gambar 6. Intalasi power divider/combiner pada modul antena

\section{Pengukuran dan Analisis}

\subsection{Pengukuran Koefisien Refleksi/VSWR Antena}

Pengukuran antena dilakukan di laboratorium PPET. Untuk mengukur koefisien refleksi dan VSWR, alat yang digunakan adalah Network Analyzer, merek AdvantestR $3770300 \mathrm{KHz}-20$ $\mathrm{GHz}$ yang mempunyai kemampuan mengukur karakteristik antena dari frekuensi $300 \mathrm{KHz}$ sampai dengan $20 \mathrm{GHz}$. Sebelum dilakukan pengukuran, Network Analyzer beserta kabel koaxial yang dipergunakan harus dikalibrasi dengan calibration kit yang tersedia sehingga efek redaman kabel yang dipergunakan tidak diperhitungkan dalam pengukuran. Proses kalibrasi hanya dilakukan terhadap port 1 mengingat yang diukur hanya karakteristik koefisien refleksi dan VSWR antena. Langkah kalibrasi ini sangat penting untuk mendapatkan nilai validitas pengukuran sebaik mungkin. Kemudian langkah selanjutnya adalah sebagai berikut:

1. Hubungkan antena AUT (antena under test) ke port 1 Network Analyzer. Konfigurasi pengukuran koefisien refleksi dan VSWR dapat dilihat pada Gambar 7.

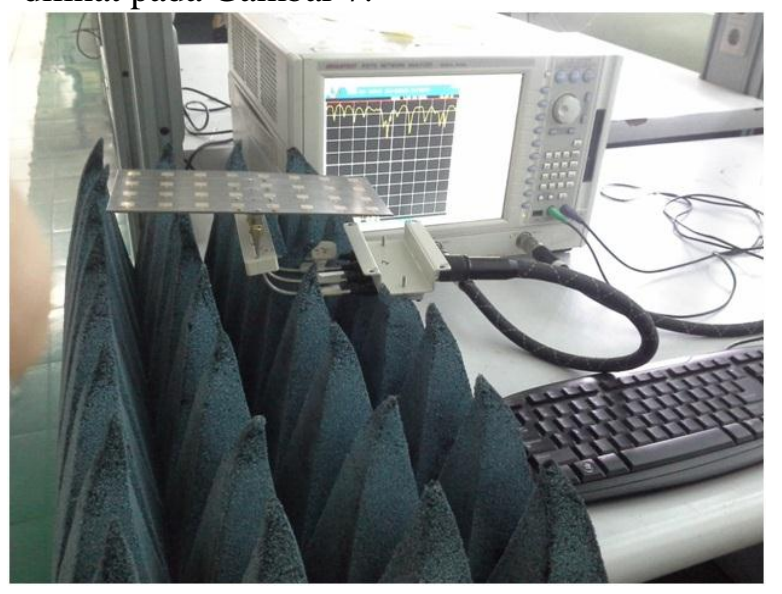

Gambar 7. Konfigurasi pengukuran koefisien refleksi dan VSWR

2. Tampilkan masing-masing parameter yang ingin diketahui melalui tombol format.

3. Pada monitor Network Analyzer akan muncul respon koefisien refleksi danVSWR sebagai fungsi dari frekuensi.

4. Simpan hasil pengukuran.

Hasil Pengukuran koefisien refleksi dan VSWR satu sub-modul antena dapat dilihat pada Gambar 8 dan 9 berikut ini.

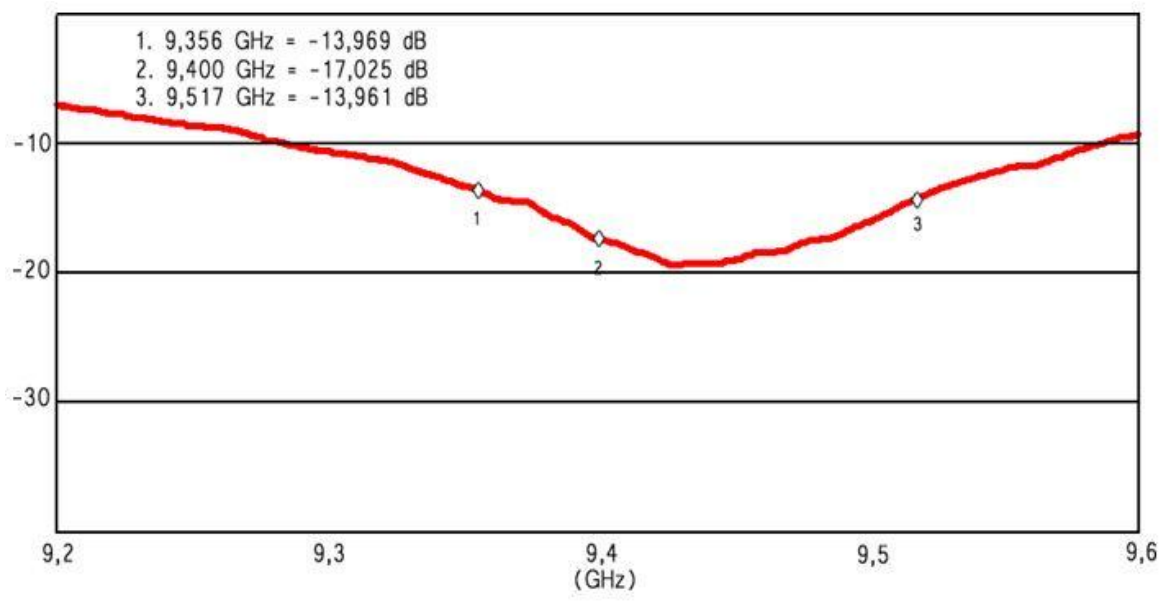

Gambar 8. Hasil pengukuran koefisien refleksi sub-modul antena 


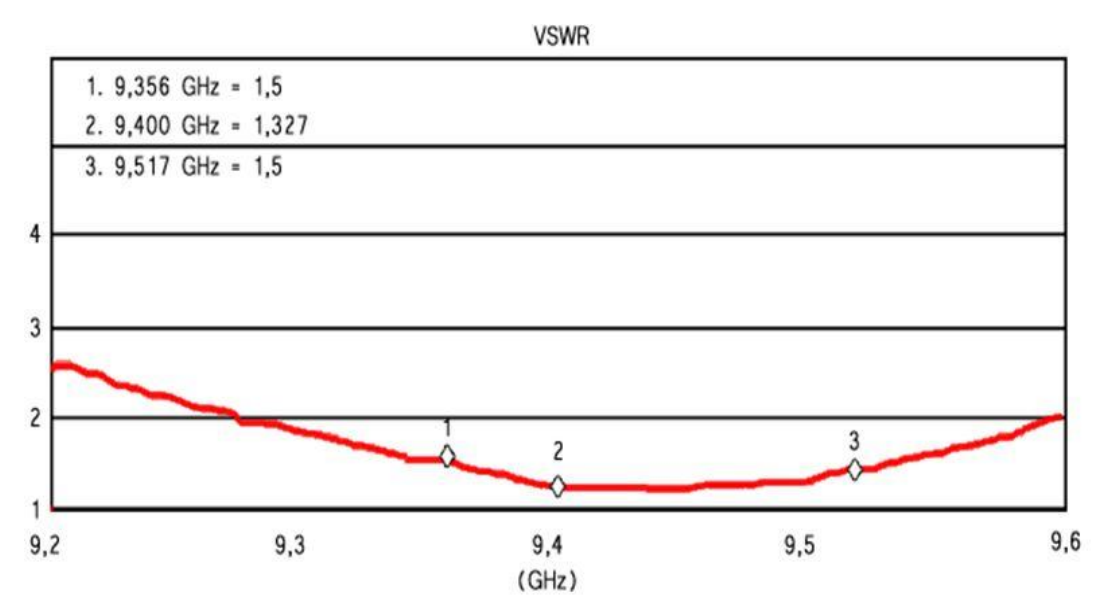

Gambar 9. Hasil pengukuran VSWR sub-modul antena

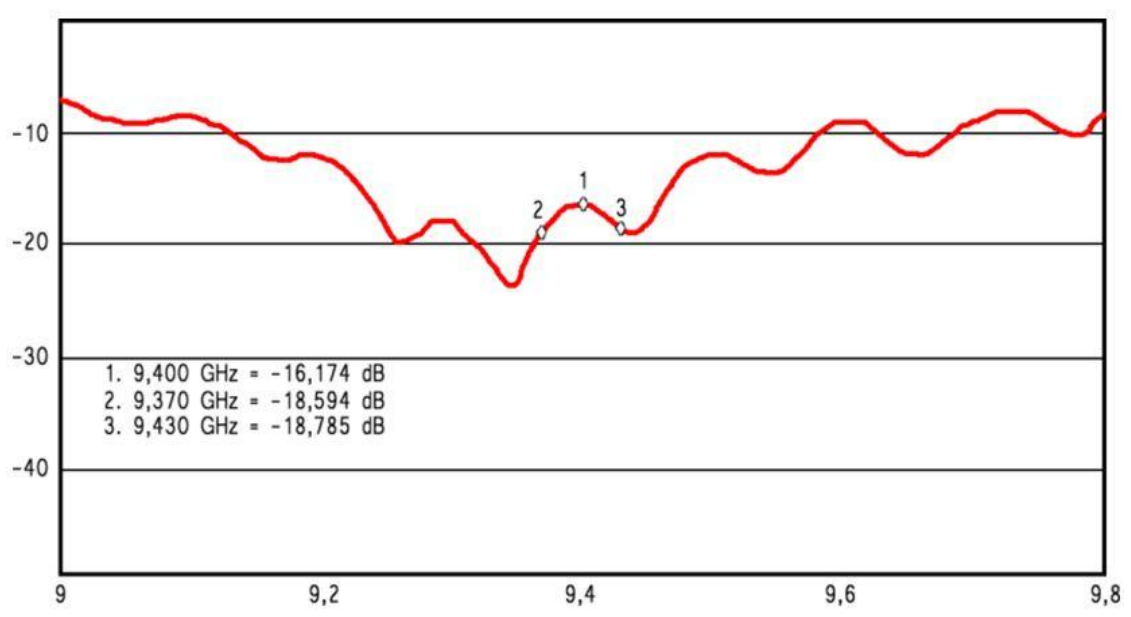

Gambar 10. Hasil pengukuran koefisien refleksi satu modul antena

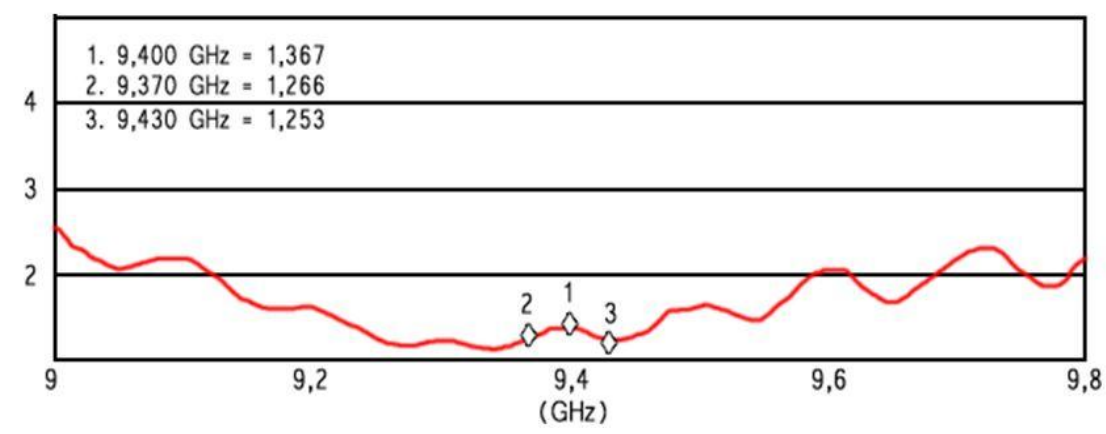

Gambar 11. Hasil pengukuran VSWR satu modul antena

Gambar 8 dan 9 merupakan hasil pengukuran koefisien refleksi dan VSWR sub-modul antena. Hasil pengukuran menunjukkan antena memiliki nilai koefisien refleksi yang bagus yaitu di bawah $15 \mathrm{~dB}$ pada frekuensi $9,4 \mathrm{GHz}$ yaitu $-17,025 \mathrm{~dB}$. Gambar 9 menunjukkan bahwa desain antena memiliki frekuensi operasi 9,356-9,517 GHz dengan nilai VSWR kurang dari 1,5 sehingga bandwidth dari antena desain $161 \mathrm{MHz}$. Sistem radar dirancang untuk beroperasi pada $9,4 \mathrm{GHz}$ frekuensi. Dari hasil pengukuran menunjukkan bahwa antena telah dirancang sesuai dengan spesifikasi yang diinginkan yaitu pada frekuensi
9,4 GHz sub-modul antena memiliki nilai VSWR sebesar 1,327.

Pengukuran dari empat antena sub-modul yang telah digabungkan dengan menggunakan power combiner/divider juga diperlukan untuk memastikan proses penggabungan antena dengan menggunakan power combiner/divider tidak mempengaruhi nilai koefisien refleksi dan antena VSWR. Hasil pengukuran koefisien refleksi dan VSWR dari modul antena ditunjukkan pada Gambar 10 dan 11. Dari gambar dapat dilihat pengukuran hasil dari koefisien refleksi antena dan VSWR masih sesuai dengan spesifikasi yang diinginkan yaitu antena mempunyai nilai VSWR kurang dari 1,5 untuk frekuensi kerja 9,4 GHz. 
Hasil pengukuran koefisien refleksi satu modul antena pada frekuensi $9,4 \mathrm{GHz}$ diperoleh sebesar $-16,174 \mathrm{~dB}$ yang ditunjukkan pada Gambar 10 . Sedangkan nilai VSWR dari satu modul antena pada frekuensi operasi $9,4 \mathrm{GHz}$ yaitu 1,367 seperti ditunjukkan pada Gambar 11. Hal ini menunjukkan bahwa penambahan power combiner/divider tidak berpengaruh pada kinerja antena.

\subsection{Pengukuran Gain}

Metode pengukuran gain ada 2 macam yaitu pengukuran absolute dan pengukuran dengan pembanding. Untuk pengukuran dengan pembanding diperlukan antena pembanding dan juga estimasi gain. Antena yang sering digunakan sebagai referensi adalah antena dipole $\lambda / 2$ dan antena corong piramida (horn) [14].

Pengukuran gain yang dilakukan pada penelitian ini menggunakan metode pembanding yaitu dengan menggunakan antena horn sebagai antena referensi. Port 1 dari Signal Generator dihubungkan ke Antena Sumber sebagai Transmitter (Tx) dan Port 2 pada Spectrum Analyzer dihubungkan ke modul antena dan antena referensi yang bertindak sebagai receiver $(\mathrm{Rx})$. Konfigurasi pengukuran gain dapat dilihat pada Gambar 12. Jarak minimum medan jauh antara antena pengirim dan antena penerima dalam proses pengukuran gain dinyatakan dalam rumus sebagai berikut (14):

$$
r_{\min }=\frac{2 D^{2}}{\lambda}
$$

Dimana:

$r_{\min }=$ jarak minimum pemancar dengan penerima

$D \quad=$ dimensi terbesar dari antena

$\lambda \quad=$ panjang gelombang

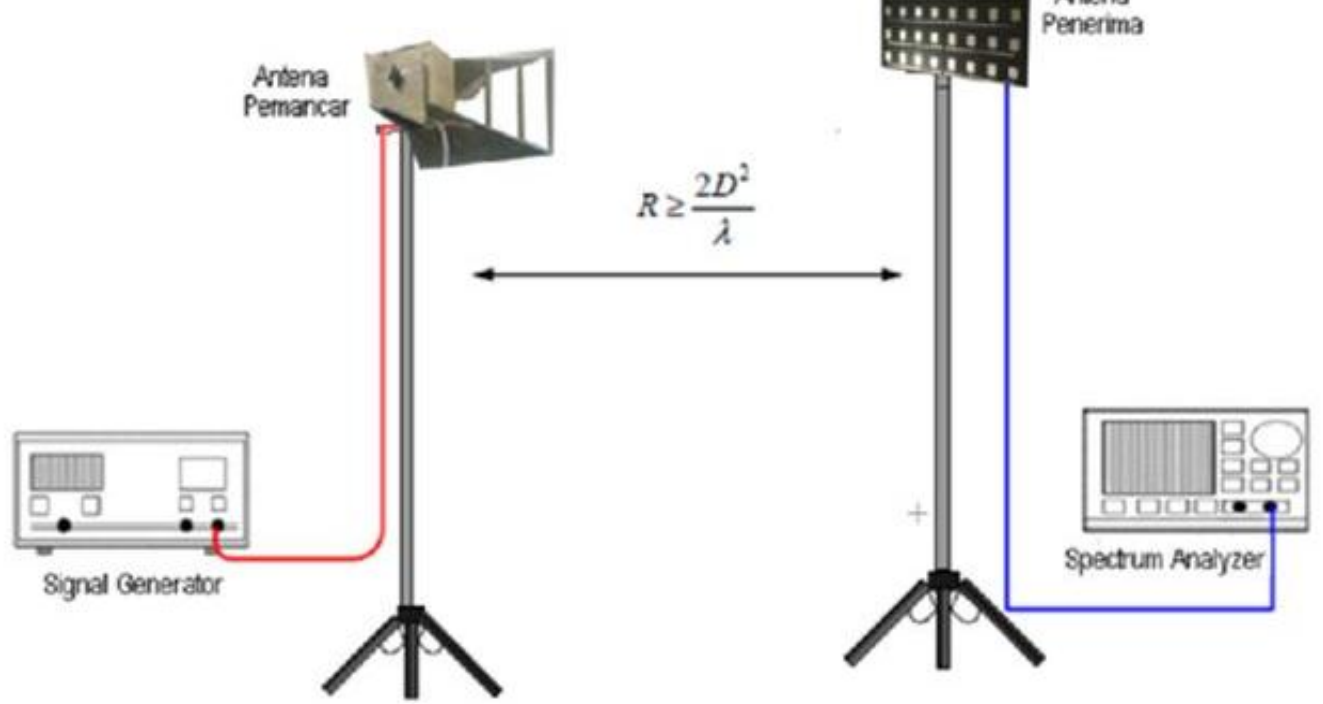

(a)

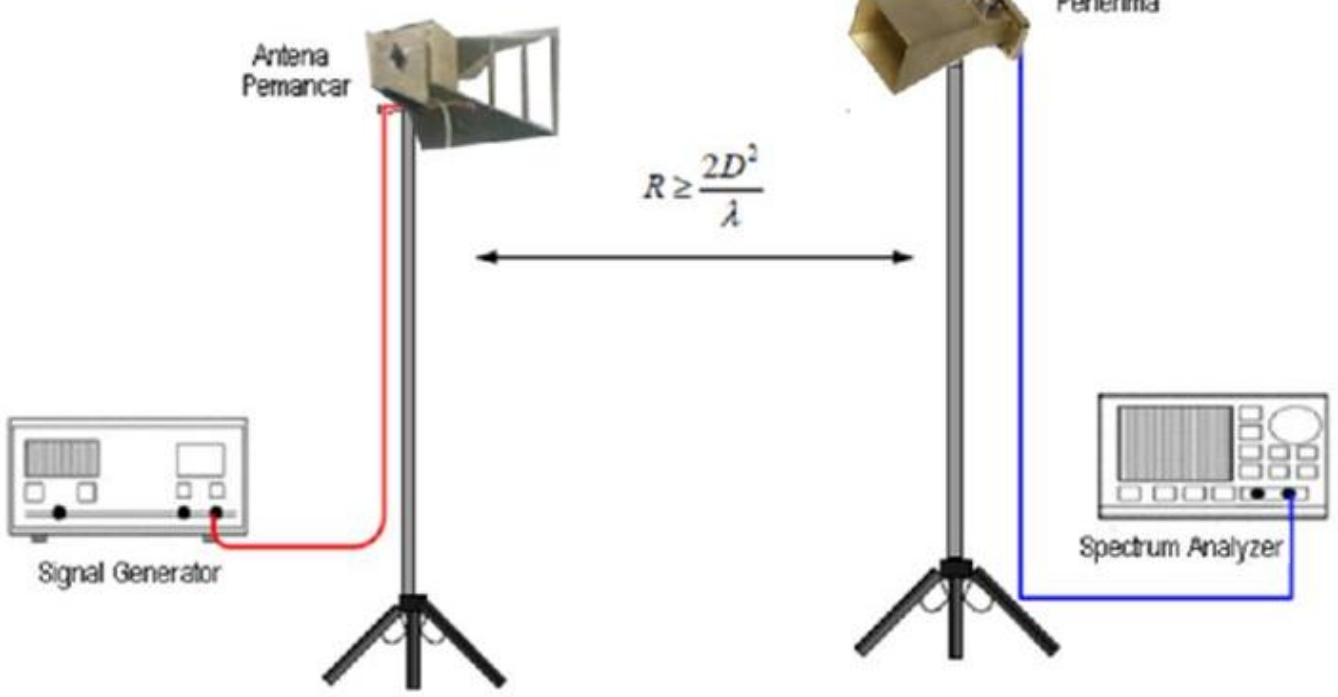

(b)

Gambar 12. Konfigurasi pengukuran gain (a). Modul Antena sebagai penerima, (b). Antena referensi sebagai penerima 
Tabel 1. Hasil pengukuran gain satu modul antena

\begin{tabular}{ccc}
\hline No & $\begin{array}{c}\text { Daya Terima Max } \\
\text { AUT }(\mathrm{dBm})\end{array}$ & $\begin{array}{c}\text { Daya Terima Max } \\
\text { Referensi }(\mathrm{dBm})\end{array}$ \\
\hline 1. & -36.25 & -47.27 \\
2. & -36.46 & -46.01 \\
3. & -36.12 & -47.38 \\
4. & -35.31 & -47.81 \\
5. & -36.11 & -46.68 \\
6. & -36.02 & -47.25 \\
7. & -36.54 & -47.05 \\
8. & -36.61 & -48.22 \\
9. & -35.27 & -47.19 \\
10. & -36.43 & -47.06 \\
Average & -36.112 & -47.192 \\
Gain & 20.08 & \\
(dBi) & & \\
\hline
\end{tabular}

Hasil pengukuran gain antena ditunjukkan pada Tabel 1. Pengukuran Gain dilakukan dengan membandingkan penerimaan daya maksimum antena radar dengan penerimaan daya maksimum antena referensi. Pengukuran menggunakan antena horn sebagai antena referensi dengan frekuensi 9.4 $\mathrm{GHz}$, sehingga pengukuran gain antena yang diuji dapat dihitung dengan persamaan sebagai berikut:

$$
G a(d B i)=P a(d B m)-P s(d B m)+G s(d B i)
$$

dimana:
$\mathrm{Pa}(\mathrm{dBm})=$ Daya Terima Max AUT $(\mathrm{dBm})$

Ps $(\mathrm{dBm})=$ Daya Terima Max Referensi $(\mathrm{dBm})$

$\mathrm{Gs}(\mathrm{dBi})=$ Gain antena referensi

Untuk mendapatkan hasil yang akurat, pengukuran penerimaan daya maksimum dilakukan sebanyak sepuluh kali, kemudian diambil nilai rata-rata masing-masing daya yang diterima pada antena radar dan antena referensi, selanjutnya dari nilai rata-rata dapat dihitung Gain antena radar. Hasil pengukuran gain satu modul antena adalah 20,08 dBi.

\subsection{Pengukuran Pola Radiasi Antena}

Pola radiasi antena merupakan gambaran dari itensitas pancaran antena sebagai fungsi koordinat bola $(\Phi, \theta)$. Pola radiasi diperoleh dengan membuat pola elevation ( $\Phi$ tetap, $\theta$ variabel) atau pola azimuth ( $\Phi$ variabel, $\theta$ tetap).

Pada pengukuran pola radiasi digunakan antena horn sebagai pemancar dan antena under test sebagai penerima. Antena pemancar dihubungkan dengan signal generator sedangkan antena penerima dihubungkan dengan spectrum analyzer. Berikut ini adalah gambar setup pengukuran pola radiasi.

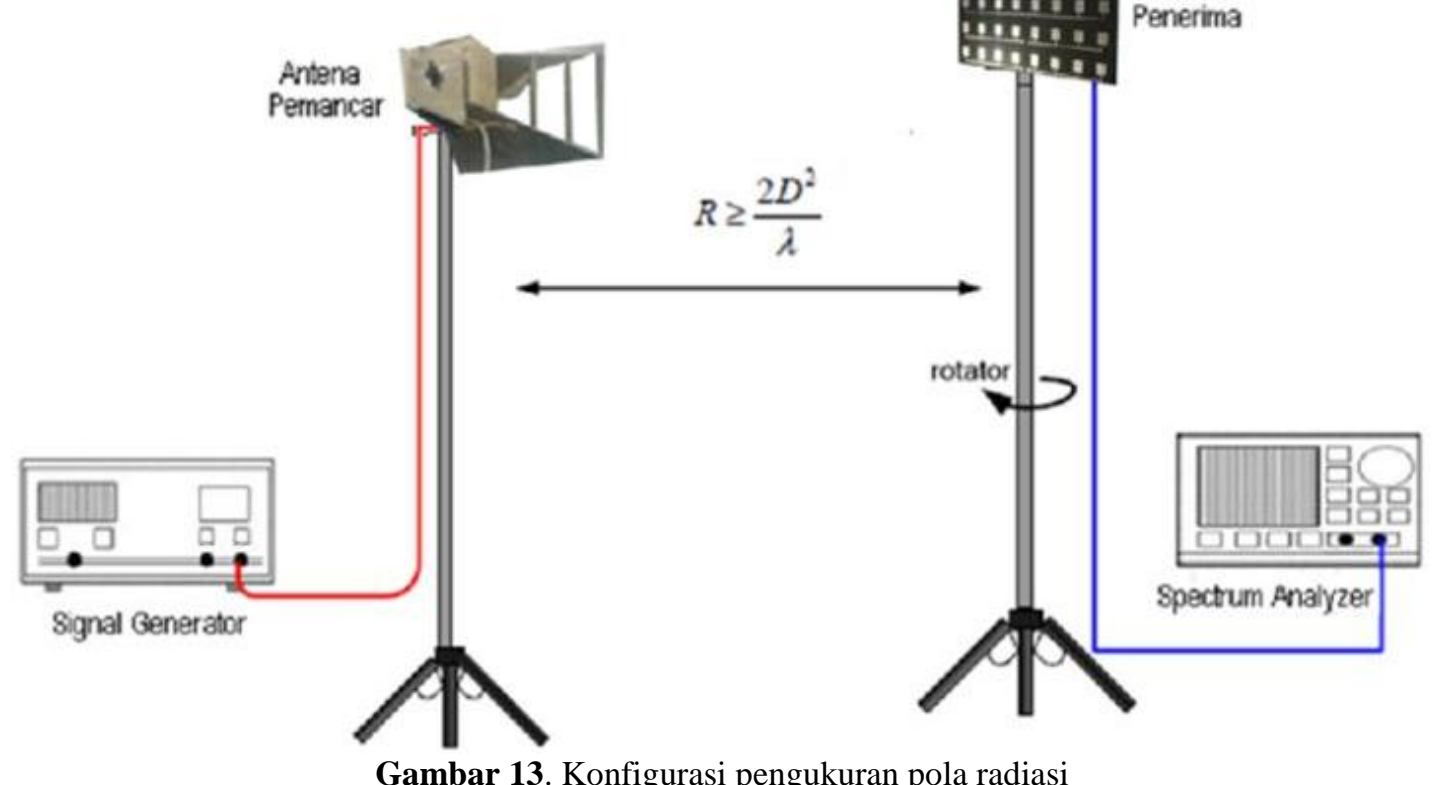

Modul Antena dengan Susunan Uniform....: F. Oktafiani, Y. P. Saputera, Y. Y. Maulana, Y. Wahyu • 15 


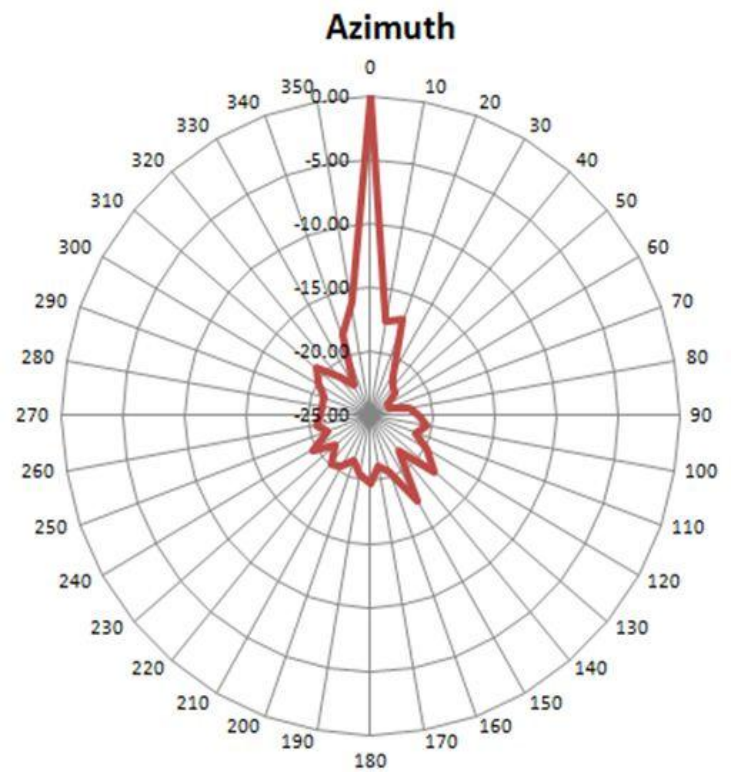

(a).

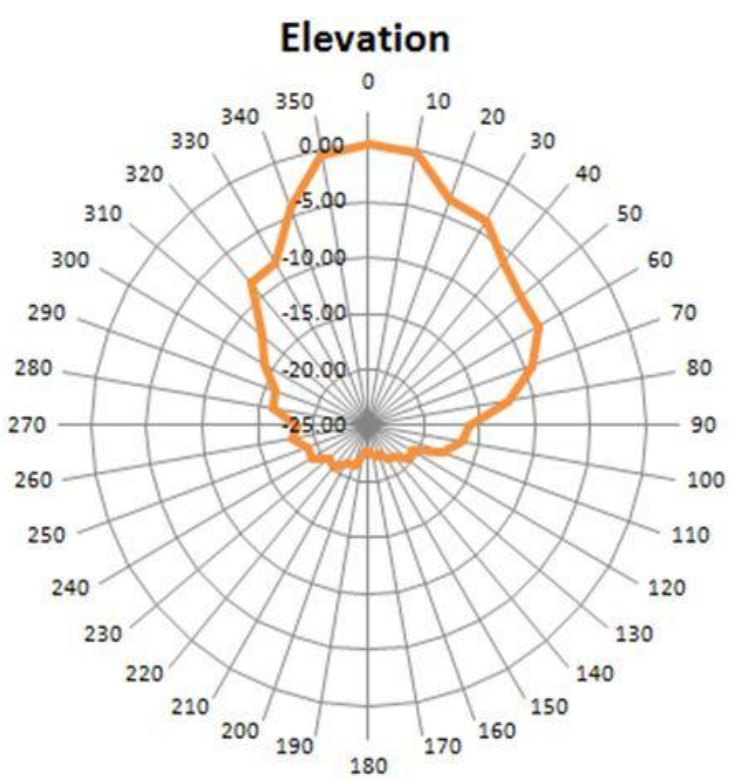

(b).

Gambar 14. Hasil pengukuran pola radiasi satu modul antena (a). beamwidth azimuth, (b). beamwidth elevation

Pengukuran satu modul antena menghasilkan pola radiasi seperti ditunjukkan pada Gambar 14 . Gambar 14.(a) adalah beamwidth azimuth (horizontal) dari satu modul antena yaitu sebesar $10^{\circ}$ pada $-3 \mathrm{~dB}$, dan Gambar 14.(b) adalah beamwidth elevation (vertikal) dari satu modul antena yaitu sebesar $20^{\circ}$ pada $-3 \mathrm{~dB}$.

\section{Analisis}

Karakteristik modul antena generasi kedua telah dipaparkan pada pembahasan 4. Berdasarkan hasil pengukuran maka perbandingan performansi antara modul antena generasi pertama dan generasi kedua dapat dilihat pada Tabel 2 berikut ini.

Tabel 2. Perbandingan performansi modul antena

\begin{tabular}{lll}
\hline \multicolumn{1}{c}{ Parameter } & \multicolumn{1}{c}{ Generasi I } & \multicolumn{1}{c}{ Generasi II } \\
\hline Dimensi (p x 1) & $57 \times 190$ & $89 \times 188.96$ \\
Jumlah Patch & 8 buah & 32 buah \\
VSWR & 1,0207 & 1.367 \\
Koefisien Refleksi & $-37,469 \mathrm{~dB}$ & $-16.174 \mathrm{~dB}$ \\
Gain & $15.4 \mathrm{~dB}$ & $20.08 \mathrm{~dB}$ \\
Beamwidth & $10^{\circ}$ & $10^{\circ}$ \\
Horizontal & & $20^{\circ}$ \\
Beamwidth Vertikal & $106.6^{\circ}$ & \\
\hline
\end{tabular}

Lebar modul antena generasi pertama dan kedua mempunyai ukuran yang hampir sama yaitu 190mm, hal ini disebabkan karena masing masing modul antena terdiri dari 8 buah patch yang disusun secara horizontal. Panjang modul antena generasi pertama berkisar dua pertiga dari panjang modul antena generasi kedua. Penambahan panjang modul antena generasi kedua merupakan kompensasi dari adanya susunan antena secara vertikal.

Jumlah patch modul antena generasi kedua empat kali lipat dari generasi pertama yaitu sebanyak 32 buah. Tujuan dari penambahan patch pada arah vertikal untuk memperkecil beamwidth vertikal dan juga untuk meningkatkan gain.

Nilai VSWR modul antena generasi pertama dan kedua menunjukkan bahwa antena memenuhi spesifikasi desain antena untuk radar yaitu dibawah 1,5 atau sebanding dengan nilai koefisien refleksi $-14 \mathrm{~dB}$. VSWR dan koefisien refleksi modul antena generasi pertama menunjukkan nilai yang lebih baik, namun merupakan pengukuran pada frekuensi 9,4181 GHz. Hal ini menunjukan modul antena generasi pertama mengalami pergeseran frekuensi operasi dari spesifikasi yang diinginkan yaitu frekuensi kerja 9,4 GHz.

Gain modul antena generasi kedua yaitu 20,08 $\mathrm{dB}$, hal ini disebabkan karena dengan menyusun antena secara array dapat meningkatkan gain antena. Penambahan gain antena dengan menyusun antena secara array yaitu $10 \log \mathrm{N}$, dimana $\mathrm{N}$ merupakan jumlah patch antena yang digunakan, sehingga peningkatan gain antena berbanding lurus secara logaritmik dengan jumlah patch yang disusun array. Modul antena sistem antena radar generasi pertama menghasilkan gain sebesar 15,45 dB sehingga modul antena sistem antena radar generasi kedua yang didesain mempunyai gain yang lebih tinggi $\pm 5 \mathrm{~dB}$.

Delapan patch yang tersusun secara horizontal pada modul antena generasi pertama dan kedua menghasilkan beamwidth horizontal yang sama yaitu $10^{\circ}$. Perbedaan signifikan dapat dilihat pada beamwidth vertikal antena. Dengan menambahkan susunan antena secara vertikal pada modul antena generasi kedua terbukti menghasilkan beamwidth vertikal lima kali lebih sempit dibandingkan modul antena generasi pertama. 
Beamwidth vertikal antena sistem antena radar generasi pertama sebesar $20^{\circ}$, nilai ini diperoleh dengan adanya penambahan reflektor sehingga pola radiasi antena dapat terfokuskan pada sudut beamwidth tertentu. Beamwidth vertikal modul antena sistem antena radar generasi kedua sudah sama dengan generasi pertama yaitu $20^{\circ}$. Hal ini membuktikan bahwa susunan antena secara vertikal dapat mempersempit beamwidth vertikal tanpa menggunakan reflektor.

\section{Kesimpulan}

Modul antena untuk sistem antena radar generasi kedua telah didesain dan dapat bekerja pada frekuensi $9.4 \mathrm{GHz}$. Modul antena yang didesain mempunyai gain yang lebih tinggi dibandingkan dengan modul antena untuk sistem antena radar generasi pertama sehingga tidak memerlukan reflektor sebagai penambah gain antena. Dengan menghilangkan reflektor pada sistem antena maka sistem antena generasi kedua mempunyai dimensi yang lebih ringan dibandingkan dengan generasi pertama. Penambahan susunan antena ke arah vertikal juga mempengaruhi kinerja modul antena yaitu di sisi beamwidth vertikal sehingga secara keseluruhan modul antena generasi ke dua yang telah didesain mempunyai performansi yang lebih baik dari generasi pertama.

\section{Ucapan Terimakasih}

Penelitian ini didanai dari program Insentif Riset SINAS tahun 2015 oleh Kementrian Riset, Teknologi dan Pendidikan Tinggi Republik Indonesia. Penulis berterima kasih kepada Departemen Teknik Elektro Universitas Indonesia, atas kerjasamanya.

\section{Daftar Pustaka}

[1] M.I. Skolnik, Radar Handbook, McGraw-Hill, 1990.

[2] M.I. Skolnik, Introduction to Radar Sistems, McGraw-Hill, 2002.

[3] S. Kingsley and S. Quegan, Understanding Radar Sistems, CHIPS.

[4] Leo P. Ligthart, Short Course on Radar Technologies, International Research Centre for Telecommunications-transmission and Radar, TU Delft, September 2005.

[5] Balanis, Constantine A, Antena Theory Analysis and Design, 3rd edition, Willey Inc, 2005.

[6] R. Garg, P. Bartia, I. Bahl and A. Ittipiboon, Microstrip Antenna Design Handbook, Norwood: Artech House, Inc., 2001.

[7] V. R. Gupta and N. Gupta, Characteristics of a Compact Microstrip Antenna, Microwave and Optical Technology Letters, vol. 40, no. 2, pp. 158160, 2004.
[8] R. Mishra, P. Kuchhal, A. Kumar. Effect of Height of the Substrate and Width of the Patch on the Performance Characteristics of Microstrip Antenna. International Journal of Electrical and Computer Engineering (IJECE). Vol. 5, No. 6, December 2015, pp. 1441-1445.

[9] Muhammad Darsono, Endra Wijaya. Circularly Polarized Proximity-Fed Microstrip Array Antenna for Micro Satellite. TELKOMNIKA, Vol.11, No.4, December 2013, pp. 803-810.

[10] Sri Hardiati, Yusuf Nur Wijayanto, Sulistyaningsih, Pamungkas Daud, Pencatuan Antena Patch Array pada Aplikasi Radar Maritim, industrial Electronics Seminar, Surabaya, 2008.

[11]Pamungkas Daud, Yusuf Nur Wijayanto, Sulistyaningsih, Sri Hardiati, Antena Mikrostrip Patch Array untuk Aplikasi Sistem Radar Maritim, Pemaparan Hasil Litbang Ilmu Pengetahuan Teknik IV, Bandung, 2008.

[12] Pamungkas Daud, Yuyu Wahyu, Mashury, Folin Oktafiani, Sulistyaningsih, Sri Hardiati, Desain dan Realisasi Struktur Penunjang Fisik Sistem Antena Radar Pantai, Seminar Radar Nasional 2008, Jakarta, 2008.

[13] Garge Ramesh, Microstrip Antena Design Handbook, Artech House Inc, 2001.

[14] John D. Kraus, Antennas for All Appilcation 3nd Edition, New delhi: Tata MC Graw-Hill Publishing Company Limited, 2003. 
18 - INKOM, Vol. 10 No. 1, September 2016: 09-18 